\title{
EXPERIMENTOS EN CIENCIAS SOCIALES: ENERGÍAS RENOVABLES Y POBREZA \\ ENERGÉTICA EN EL SUR DE LA PROVINCIA DE BUENOS AIRES-ARGENTINA
}

\section{EXPERIMENTS IN SOCIAL SCIENCES: RENEWABLE ENERGIES AND ENERGY POVERTY IN THE SOUTH OF THE PROVINCE OF BUENOS AIRES-ARGENTINA}

\author{
Fernando Antonio González \\ Instituto de Investigaciones Económicas \\ y Sociales del Sur, UNS/CONICET \\ Departamento de Economía, \\ Universidad Nacional del Sur \\ Bahía Blanca, Buenos Aires, Argentina \\ faigonzalez@iiess-conicet.gob.ar \\ María Florencia Zabaloy \\ Instituto de Investigaciones Económicas \\ y Sociales del Sur, UNS/CONICET \\ Departamento de Economía, \\ Universidad Nacional del Sur \\ Bahía Blanca, Buenos Aires, Argentina \\ florenciazabaloy@gmail.com
}

\author{
Mauro David Reyes Pontet \\ Instituto de Investigaciones Económicas \\ y Sociales del Sur, UNS/CONICET \\ Departamento de Economía, \\ Universidad Nacional del Sur \\ Bahía Blanca, Buenos Aires, Argentina \\ maurod.reyes@gmail.com
}

María María Ibáñez Martín

Instituto de Investigaciones Económicas

y Sociales del Sur, UNS/CONICET

Departamento de Economía,

Universidad Nacional del Sur

Bahía Blanca, Buenos Aires, Argentina mariamariaibanez@gmail.com

\section{Silvia London \\ Instituto de Investigaciones Económicas \\ y Sociales del Sur, UNS/CONICET \\ Departamento de Economía, \\ Universidad Nacional del Sur \\ Bahía Blanca, Buenos Aires, Argentina slondon@uns.edu.ar}

Fecha de recepción: 11/09/2020 - Fecha de revisión: 03/11/2020 - Fecha de aprobación: 31/12/2020

DOI: https://doi.org/10.36995/j.visiondefuturo.2021.25.02.005.es

\section{RESUMEN}

La existencia, en el hogar, de privaciones en el acceso a servicios básicos se torna especialmente relevante en el actual contexto de pandemia por la enfermedad del coronavirus 2019 (COVID-19). En este trabajo se presentan los resultados obtenidos en la primera etapa del proyecto Energías renovables como herramienta de reducción de la pobreza energética. Una prueba piloto en barrios vulnerables de Bahía Blanca. El mismo tiene por objetivo la implementación de colectores solares para brindar, a hogares en barrios vulnerables, agua caliente sanitaria y evaluar su impacto a partir de una metodología de ensayos aleatorios controlados.

Se presenta una caracterización socioeconómica de la población objetivo considerando relevamientos previos y avances en nuevos relevamientos. También se detalla la planificación metodológica de la intervención, con especial énfasis en las modificaciones que debieron realizarse debido al contexto de aislamiento social.

\footnotetext{
"Visión de Futuro" Año 18, Volumen N²5 N² 2, Edición Especial-III Congreso Regional de Economía del Norte Grande-Pág 101-123 URL de la Revista: http://visiondefuturo.fce.unam.edu.ar/index.php/visiondefuturo/index URL del Documento: https://visiondefuturo.fce.unam.edu.ar/index.php/visiondefuturo/issue/view/20 ISSN 1668 - 8708 - Versión en Línea E-mail: revistacientifica@fce.unam.edu.ar

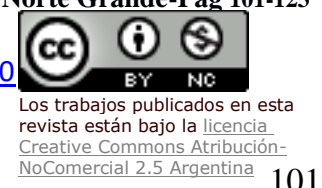


Los resultados sugieren que los hogares del barrio 9 de Noviembre se encuentran ampliamente rezagados en términos de desarrollo y bienestar en relación al promedio de la ciudad. Esta situación es una constante según surge de, al menos, dos relevamientos de hogares (2016 y 2020). En la implementación de ensayos controlados en Economía, se concibe esencial la consideración explícita de aquellos factores no controlables por el investigador.

PALABRAS CLAVE: Ensayos Aleatorios Controlados; Pobreza Energética, Vulnerabilidad, Energías Renovables, Bahía Blanca.

\section{ABSTRACT}

The existence, at home, of deprivations in access to basic services becomes especially relevant in the current context of the pandemic due to the coronavirus disease 2019 (COVID19). This paper presents the results obtained in the first stage of the Renewable Energies project as a tool for reducing energy poverty. A pilot test in vulnerable neighborhoods in Bahía Blanca. It aims to implement solar collectors to provide households in vulnerable neighborhoods with sanitary hot water and evaluate its impact based on a methodology of randomized controlled trials.

A socioeconomic characterization of the target population is presented considering previous surveys and advances in new surveys. The methodological planning of the intervention is also detailed, with special emphasis on the modifications that had to be made due to the context of social isolation.

The results suggest that households in the 9 de Noviembre neighborhood lag far behind in terms of development and well-being in relation to the city average. This situation is a constant as it arises from at least two household surveys (2016 and 2020). In the implementation of controlled trials in Economics, the explicit consideration of those factors not controllable by the researcher is essential.

KEY WORDS: Randomized Controlled Trials; Energy Poverty; Vulnerability; Renewable Energy, Bahía Blanca.

\section{INTRODUCCIÓN}

La existencia, en el hogar, de privaciones energéticas y, en general, de privaciones habitacionales y de acceso a servicios es un factor que contribuye a agravar una situación de pobreza -entendida ésta desde una óptica multidimensional-. Por ello, la consideración de

\footnotetext{
“Visión de Futuro" Año 18, Volumen N²5 N 1, Edición Especial-III Congreso Regional de Economía del Norte Grande-Pág 101-123 URL de la Revista: http://visiondefuturo.fce.unam.edu.ar/index.php/visiondefuturo/index

URL del Documento: https://visiondefuturo.fce.unam.edu.ar/index.php/visiondefuturo/issue/view/20

ISSN 1668 - 8708 - Versión en Línea

E-mail: revistacientifica@fce.unam.edu.ar
} 
este grupo de privaciones es relevante. En efecto, su inclusión en la medición de la pobreza es frecuente -tanto a nivel global como local- (Alkire y Santos, 2010; Arévalo y Paz, 2014; Santos y Villatoro, 2018).

En el actual contexto de aislamiento social, la relevancia de este conjunto de privaciones es aún mayor. La Organización Mundial de la Salud (2020) recomienda como medidas preventivas ante la pandemia, además del aislamiento, una adecuada higienización y unfácil acceso a los servicios de salud en caso de presentar síntomas. La implementación de estas recomendaciones requiere de condiciones mínimas de habitabilidad y acceso a servicios. Así, es evidente que hogares pobres se ven imposibilitados de protegerse en forma adecuada ante el virus (Brown, Ravallion y van de Walle, 2020).

Un reducido tamaño, materiales precarios o una localización en lejanías de los centros de salud disminuyen la capacidad de los miembros del hogar de aislarse y protegerse. En igual sentido opera la falta de acceso a agua sanitaria dentro del hogar. En otras palabras, ser pobre reduce ampliamente la capacidad de protegerse ante el virus (Ravallion, 2020). Por ello, la implementación de políticas de reducción de privaciones en el acceso a servicios básicos se torna especialmente relevante.

En este trabajo se presenta un estudio de caso de un barrio vulnerable con severas privaciones en el acceso y calidad de servicios energéticos en la ciudad de Bahía Blanca, ubicada al sur de la provincia de Buenos Aires, Argentina. El objetivo es presentar los primeros avances y la propuesta metodológica para la implementación de colectores solares en hogares del barrio 9 de Noviembre, con el fin de ampliar el acceso a Agua Caliente Sanitaria (ACS) de su población y reducir la incidencia de la pobreza energética. En particular, se plantea una metodología basada en ensayos aleatorios y se presenta una discusión sobre su aplicabilidad en el campo de las ciencias sociales.

A tal fin el trabajo se estructura de la siguiente manera. En el siguiente apartado se realiza una caracterización tanto de la ciudad de Bahía Blanca como del barrio 9 de Noviembre, donde se lleva a cabo el proyecto. En el tercer apartado se expone el diseño del proyecto según sus diferentes etapas. En la cuarta sección se muestran las diversas adaptaciones que debieron ejecutarse sobre la propuesta original debido a la cuarentena por la pandemia del COVID-19, y se remarcan los avances alcanzados hasta el momento. Por último, se presentan las reflexiones finales.

\footnotetext{
"Visión de Futuro" Año 18, Volumen No 25 Nº 1, Edición Especial-III Congreso Regional de Economía del Norte Grande-Pág 101-123 URL de la Revista: http://visiondefuturo.fce.unam.edu.ar/index.php/visiondefuturo/index

URL del Documento: https://visiondefuturo.fce.unam.edu.ar/index.php/visiondefuturo/issue/view/20

ISSN 1668 - 8708 - Versión en Línea

E-mail: revistacientifica@fce.unam.edu.ar
} 


\section{DESARROLLO}

\section{La ciudad de Bahía Blanca y el Barrio 9 de Noviembre}

\subsection{Bahía Blanca: breve revisión de indicadores socioeconómicos y desarrollo} urbano

Fundada el 11 de abril de 1828, la ciudad de Bahía Blanca (cabecera del partido homónimo) se ubica en el sudoeste de la provincia de Buenos Aires, Argentina. Cuenta con aproximadamente 301 mil habitantes según el último censo (2010) sobre una superficie total de 2247 kilómetros cuadrados (véase Imagen I). La actividad económica de la ciudad se basa principalmente en el puerto de aguas profundas, a partir del cual comercia una gran diversidad de productos, la existencia de un polo petroquímico donde se ubican grandes plantas de producción industrial y un centro comercial de nivel intermedio (Gobierno Municipal de Bahía Blanca, 2020).

Los indicadores de pobreza y pobreza extrema (indigencia) se muestran poco alentadores: un $24,1 \%$ de los bahienses obtiene ingresos que los sitúan bajo la línea de pobreza, mientras que un $4,1 \%$ se encuentra en situación de indigencia, según datos recientes del Instituto Nacional de Estadísticas y Censos (INDEC, 2019). Santos (2020), bajo una perspectiva multidimensional, indica que en el primer semestre de 2019 el 32,6\% de las personas de la ciudad mostraba condiciones de pobreza (el $24 \%$ entre pobreza severa e intensa).

Numerosos autores han señalado, previamente, la existencia de una segmentación socioeconómica y espacial en el aglomerado urbano bajo estudio. Así, en Bahía Blanca los hogares con una mejor dotación de recursos y mayores ingresos se ubican en los sectores norte, centro y oeste de la ciudad. Por el contrario, las regiones sur y este de la ciudad, principalmente regiones de la periferia urbana (donde las condiciones de clima o suelo son menos favorables para el hábitat humano) son aquellas en donde se encuentran las familias de menores ingresos y peores condiciones socioeconómicas (Pérez, 2015; Prieto, 2008; Urriza, 2018; Ramborger, Campo y Lorda, 2018).

En el mismo sentido, analizando la distribución en términos geográficos, se vislumbran en el entramado urbano de la ciudad una serie de asentamientos precarios, reconocidos en la literatura como villas, asentamientos informales o barrios populares. Hacia 2016, según el Informe de Asentamientos Informales de TECHO (2016), en Bahía Blanca existían 13 asentamientos informales que incluían 2450 familias. Otras estimaciones sugieren un número incluso mayor de barrios populares (Diaz, 2017). Estos barrios se desarrollaron, principalmente, a partir de la crisis del año 2001 con el aumento en el desempleo. El modo de conformación predominante es la denominada modalidad "hormiga", es decir espacios

\footnotetext{
"Visión de Futuro" Año 18, Volumen $\mathbf{N}^{\circ} 25$ № 1, Edición Especial-III Congreso Regional de Economía del Norte Grande-Pág 101-123 URL de la Revista: http://visiondefuturo.fce.unam.edu.ar/index.php/visiondefuturo/index

URL del Documento: https://visiondefuturo.fce.unam.edu.ar/index.php/visiondefuturo/issue/view/20

ISSN 1668 - 8708 - Versión en Línea

E-mail: revistacientifica@fce.unam.edu.ar
} 
ocupados paulatinamente. Se encuentran ubicados en terrenos fiscales (loteos sociales) o tomados ilegalmente, en zonas inundables, cercanos a basureros. Una característica importante es que los hogares evidencian privaciones en el acceso a servicios básicos (TECHO, 2016; Malisani, 2017; Diaz, 2017; Reyes Pontet y London, 2019) (Véase imagen 1).

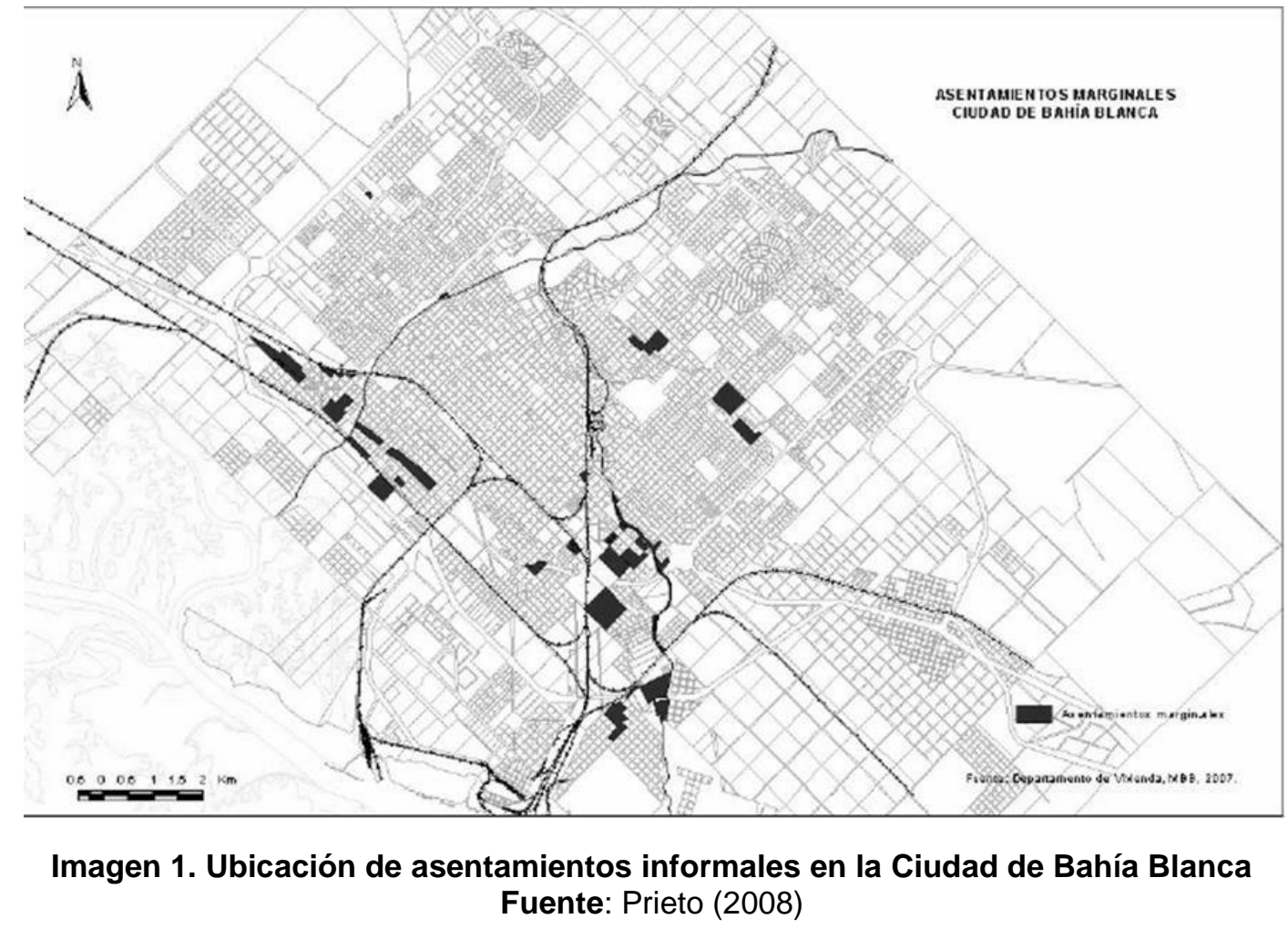

Los barrios populares de la ciudad también presentan diversas problemáticas educativas, sociales y económicas, las cuales han sido examinadas previamente desde diferentes disciplinas (Prieto, 2008; Becher y Martín, 2016; Calle, London y Pérez, 2016; Formichella, Krüger y Reyes, 2017; Ibáñez, Formichella y Costabel, 2019). Estos estudios coinciden en señalar que las personas y hogares de los barrios vulnerables de Bahía Blanca presentan niveles de educación deficientes, bajo acceso a servicios de salud, elevado desempleo, subempleo e informalidad, carencias habitacionales, falta de acceso a servicios básicos y problemas de saneamiento.

Lo anterior ha sido confirmado por Prieto (2008), que propone un indicador de vulnerabilidad que incluye la evaluación de aspectos de capital humano, social y físico. Sus resultados sugieren que los sectores periféricos de la ciudad, principalmente de las zonas sur y oeste, presentan los mayores niveles de vulnerabilidad (Imagen 2). Dentro de los barrios consignados como vulnerables se encuentra 9 de Noviembre.

\footnotetext{
"Visión de Futuro" Año 18, Volumen N$^{\circ} 25$ N 1, Edición Especial-III Congreso Regional de Economía del Norte Grande-Pág 101-123 URL de la Revista: http://visiondefuturo.fce.unam.edu.ar/index.php/visiondefuturo/index

URL del Documento: https://visiondefuturo.fce.unam.edu.ar/index.php/visiondefuturo/issue/view/20

ISSN 1668 - 8708 - Versión en Línea

E-mail: revistacientifica@fce.unam.edu.ar
} 


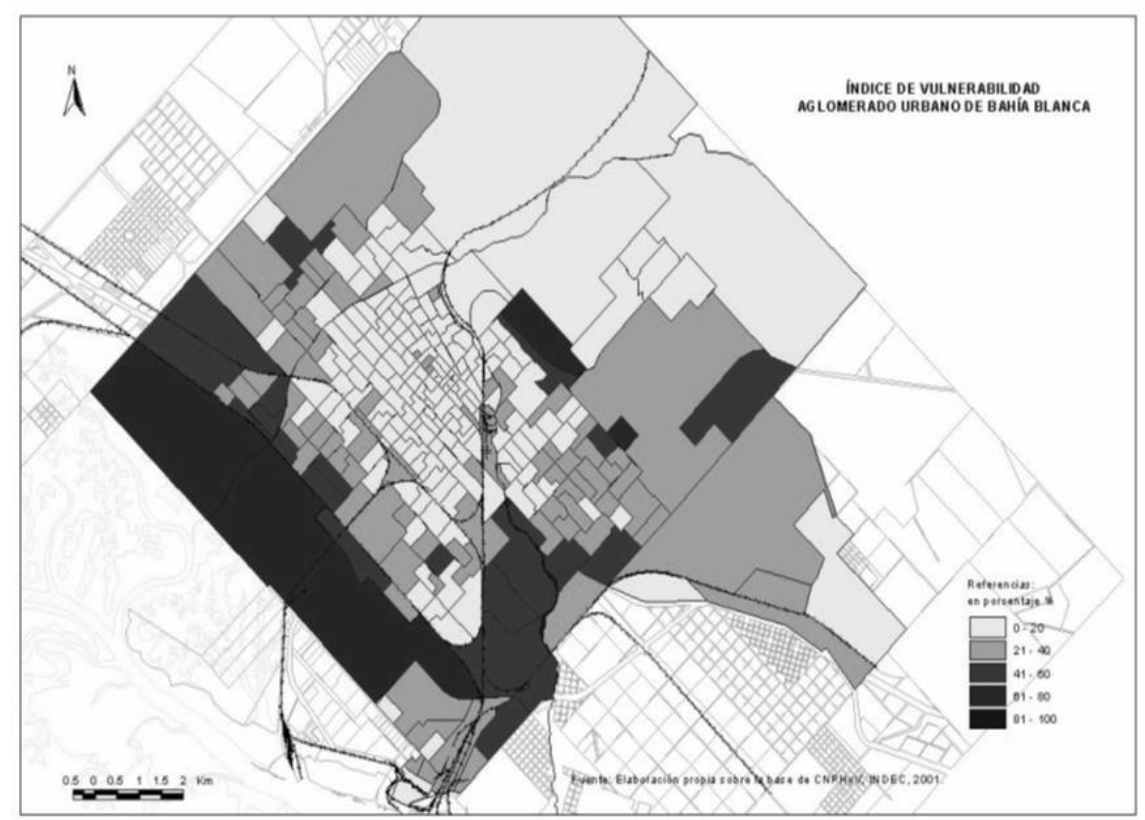

\section{Imagen 2. Vulnerabilidad en barrios de Bahía Blanca Fuente: Prieto (2008)}

\subsection{Barrio 9 de Noviembre}

El barrio 9 de Noviembre se encuentra situado en el sector noreste de la ciudad de Bahía Blanca. Comprende una superficie estimada de 23 hectáreas (Kruger y Formichella, 2018), delimitadas por las calles Parera-Punta Alta y Fragata Sarmiento-Los Naranjos (Imagen 3).

\footnotetext{
“Visión de Futuro" Año 18, Volumen No 25 N 1, Edición Especial-III Congreso Regional de Economía del Norte Grande-Pág 101-123 URL de la Revista: http://visiondefuturo.fce.unam.edu.ar/index.php/visiondefuturo/index

URL del Documento: https://visiondefuturo.fce.unam.edu.ar/index.php/visiondefuturo/issue/view/20

ISSN 1668 - 8708 - Versión en Línea

E-mail: revistacientifica@fce.unam.edu.ar
} 


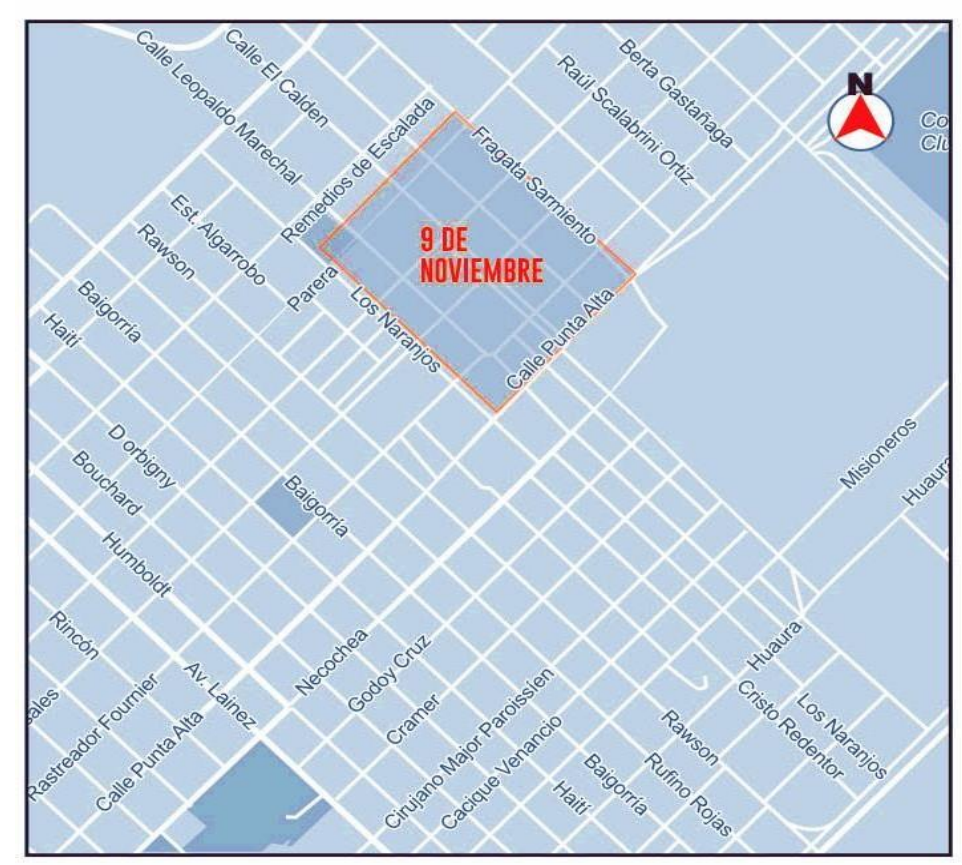

Imagen 3: delimitación del barrio 9 de Noviembre

Fuente: elaboración propia en base London et al. (2019).

Según el Registro Nacional de Barrios Populares (RENABAP, 2018), este barrio es identificado como popular. Esta caracterización implica que, al menos, el $50 \%$ de sus habitantes no posee título de propiedad de su terreno ni accede a dos o más servicios básicos (red de agua corriente, red de energía eléctrica con medidor o red cloacal). La precariedad de las condiciones de acceso a servicios y propiedad se conjuga con una alta incidencia de la pobreza por ingresos.

A partir de la información del relevamiento realizado en 2016 (London et al., 2019) ${ }^{1}$, se observa que en 9 de Noviembre el $59 \%$ de las personas se encuentra en situación de pobreza y el $18 \%$ en situación de pobreza extrema (indigencia). En otras palabras, más de la mitad de los residentes del barrio son pobres. La incidencia es casi el doble de la observada en la ciudad de Bahía Blanca, a partir de lo reportado por el INDEC, en donde menos de un cuarto de su población es pobre (Tabla 1).

Hacia adentro del barrio también se presentan profundas disparidades. Mientras que el $21 \%$ de los menores de 18 años es pobre extremo (indigente), esta proporción es del 3\% entre los mayores de 60 años. Estas magnitudes alcanzan al $66 \%$ y $44 \%$ de las personas,

\footnotetext{
${ }^{1}$ En el marco del PDTS 392, Diseño de estrategias para mejorar las oportunidades educativas de la población vulnerable de Bahía Blanca a través de la ONG Red de Voluntarios, en el cual participaron algunos de los autores de este trabajo.
}

"Visión de Futuro" Año 18, Volumen No $25 \mathbf{N}^{\mathbf{0}}$ 1, Edición Especial-III Congreso Regional de Economía del Norte Grande-Pág 101-123
URL de la Revista: http://visiondefuturo.fce.unam.edu.ar/index.php/visiondefuturo/index
URL del Documento: $\underline{\text { https://visiondefuturo.fce.unam.edu.ar/index.php/visiondefuturo/issue/view/20 }}$
ISSN 1668 - 8708 - Versión en Línea
E-mail: revistacientifica@fce.unam.edu.ar 
respectivamente, al considerar la incidencia de la pobreza (op.cit.).

Una advertencia debe ser realizada en relación a las estimaciones de incidencia de la pobreza: ambas magnitudes (barrio y ciudad) no son estrictamente comparables. Los microdatos de 9 de Noviembre se refieren a un mes particular (abril) y no a todo el trimestre de referencia (abril-junio) como los que surgen de la EPH-INDEC. Además, se realizó imputación de ingresos ante la no respuesta en los microdatos de 9 de Noviembre, mientras que INDEC procedió con re-ponderación por no respuesta. En cualquier caso, Tornarolli (2018) demuestra que la imputación de ingresos tiende a generar, para el caso argentino, estimaciones de pobreza 0,2 puntos porcentuales menores -en relación a las que se obtendrían con re- ponderación- y por lo cual, la verdadera brecha de pobreza entre el barrio y la ciudad podría estar siendo subestimada.

Tabla 1: Pobreza por ingresos en 9 de Noviembre y Bahía Blanca

\begin{tabular}{lll}
\hline & 9 & de \\
& Noviembre & $\begin{array}{l}\text { Bahía } \\
\text { Blanca-Cerri }\end{array}$ \\
\hline Pobreza extrema & 17,51 & 4,49 \\
\hline Pobreza & 59,22 & 24,03
\end{tabular}

Fuente: elaboración propia en base a London et al. (2019) y EPH-INDEC

El mayor nivel de privaciones de los hogares del barrio analizado -en relación a los de la ciudad- también es observado en otras dimensiones. Así, el $40 \%$ presenta, al menos, una Necesidad Básica Insatisfecha (NBI). Esto incluye a una vivienda precaria (11\%), hacinamiento (23\%) o instalaciones sanitarias inexistentes (31\%) (London, et al., 2019). Es preciso reconocer que los datos mencionados sobre las NBI fueron elaborados a partir de umbrales de privación conservadores. Así, una vivienda precaria consiste en locales no construidos para habitar o pensiones, mientras que se considera hacinamiento la presencia de 4 o más individuos por habitación. La carencia de instalación sanitaria se refiere a la falta de baño o inodoro.

En cuanto a la dimensión educativa, las privaciones también son más severas que en la ciudad. El 24\% de la población de 20 años o más completó el nivel medio de educación mientras que solo el $2 \%$ de los mayores de 25 años finalizó estudios de nivel terciario o universitario. En lo que respecta a los niños con edad escolar, puede verse que el problema

\footnotetext{
“Visión de Futuro" Año 18, Volumen $N^{\circ} 25$ No 1, Edición Especial-III Congreso Regional de Economía del Norte Grande-Pág 101-123 URL de la Revista: http://visiondefuturo.fce.unam.edu.ar/index.php/visiondefuturo/index

URL del Documento: https://visiondefuturo.fce.unam.edu.ar/index.php/visiondefuturo/issue/view/20

ISSN 1668 - 8708 - Versión en Línea

E-mail: revistacientifica@fce.unam.edu.ar
} 
de inasistencia está presente en el barrio. Así, el 12\% de los menores de entre 12-18 años había faltado a la escuela en la semana previa al relevamiento (London, et al., 2019).

Tabla 2: Indicadores de privación en 9 de Noviembre y Bahía Blanca

\begin{tabular}{lll}
\hline & $\begin{array}{l}\text { Barrio } 9 \\
\text { Noviembre }\end{array}$ & $\begin{array}{l}\text { de } \\
\text { Blanca-Cerri }\end{array}$ \\
\hline Indicador & $11 \%$ & $0 \%$ \\
\hline Vivienda precaria & $23 \%$ & $4 \%$ \\
\hline Hacinamiento & $31 \%$ & $0 \%$ \\
\hline Sin instalaciones sanitarias & $24 \%$ & $60 \%$ \\
\hline Logro educativo (secundaria completa) & $2 \%$ & $34 \%$
\end{tabular}

Fuente: elaboración propia en base a London et al.

(2019) Notas: aProporción de hogares con privación.

bProporción de personas de 20 años o más sin secundaria completa

c Proporción de personas de 25 años o más con educación terciaria o universitaria completa

De la Tabla 2 surgen los amplios contrastes entre el barrio y la ciudad. Así, mientras los hogares bahienses no presentan privaciones en los indicadores de vivienda precaria e instalaciones sanitarias -según lo reportado en London et al. (2019)-, 1 de cada 3 hogares de 9 de Noviembre no posee instalaciones sanitarias. En el mismo sentido, mientras 1 de cada 3 bahienses adultos posee diploma de educación superior, apenas el $2 \%$ de los residentes del barrio se encuentra en la misma situación.

En cuanto a la provisión de agua potable en el hogar, se observa que el total de las viviendas del barrio cuenta con el servicio, aunque las edificaciones más nuevas lo obtienen con conexiones clandestinas de la red general. La instalación de redes cloacales resulta dificultosa en cuanto a condiciones del terreno (desniveles), lo cual exige mayores costos para la provisión del servicio de saneamiento de efluentes y su correspondiente conexión (véase Imagen 4). A su vez, según lo reportado por Reyes Pontet e lbáñez Martín (2020) los vecinos se encuentran conectados a la red de forma ilegal y enfrentan el riesgo de corte de suministro.

\footnotetext{
"Visión de Futuro" Año 18, Volumen No 25 N 1, Edición Especial-III Congreso Regional de Economía del Norte Grande-Pág 101-123 URL de la Revista: http://visiondefuturo.fce.unam.edu.ar/index.php/visiondefuturo/index

URL del Documento: https://visiondefuturo.fce.unam.edu.ar/index.php/visiondefuturo/issue/view/20

ISSN 1668 - 8708 - Versión en Línea

E-mail: revistacientifica@fce.unam.edu.ar
} 


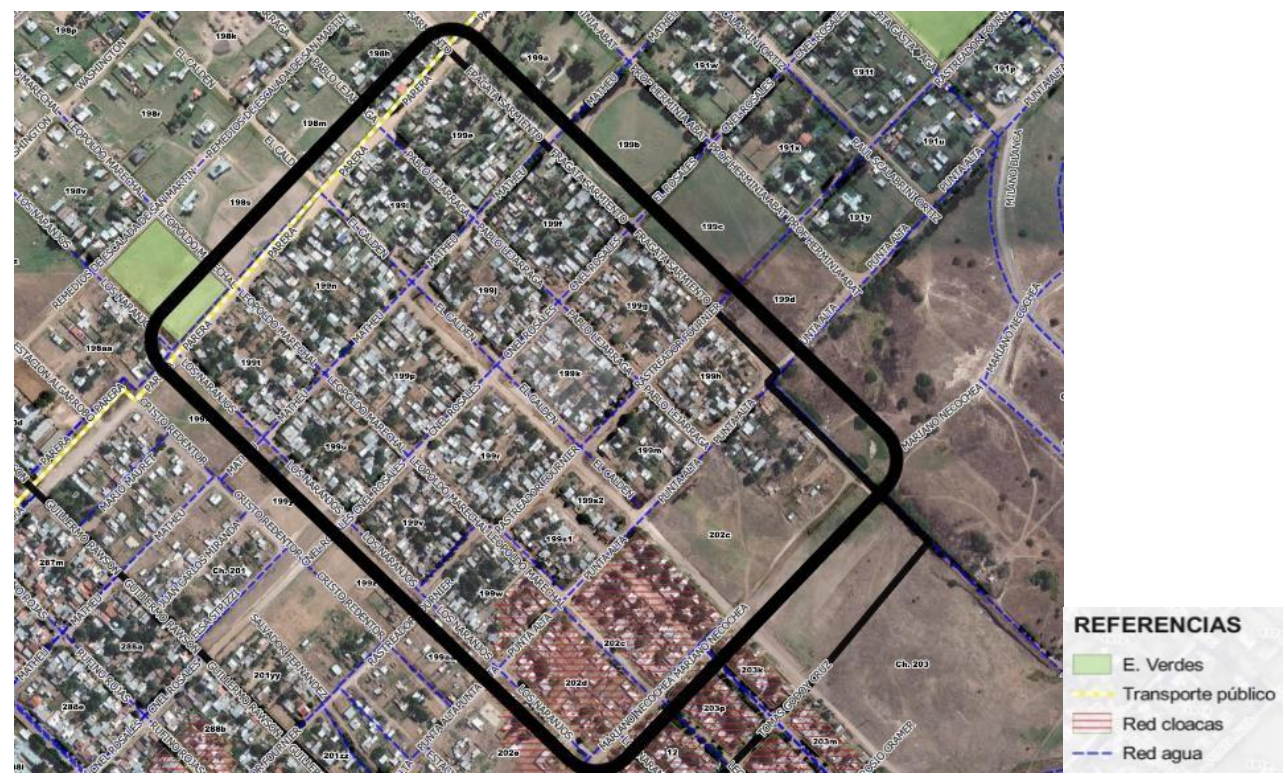

Imagen 4. Acceso red de agua potable y saneamiento cloacal en el barrio 9 de Noviembre

Fuente: Central territorial de datos del Departamento de Catastro, Municipalidad de Bahía Blanca

En relación a las privaciones energéticas, se destaca que en el barrio no está disponible la conexión a la red de gas natural. Además, pocos hogares (no más de tres) se mostraron interesados en adherirse a planificaciones de conexión al suministro de red otorgado por la empresa Camuzzi², que abarcaría en un primer momento las manzanas comprendidas entre las calles Parera-Rosales y Los Naranjos-El Caldén (cuatro manzanas de la región norte del barrio). Así, la estrategia más utilizada para la calefacción, cocción de alimentos y agua caliente sanitaria se corresponde con la utilización de Gas Licuado de Petróleo (GLP) en su presentación de garrafas. El gasto en gas envasado en algunos casos es afrontado por los vecinos, mientras que en otros por planes municipales ${ }^{3}$. A su vez, los hogares más pobres del barrio declaran utilizar, para cocción y calefacción, combustibles sólidos como leña y carbón, y en los casos más severos directamente queman residuos intradomiciliarios, tales como plásticos, gomas, pañales descartables, telgopor, cartón, entre otros -según surge de datos recolectados en entrevistas en profundidad a referentes barriales-.

Los hogares del barrio declaran utilizar electricidad de red tanto para calefacción como para agua caliente sanitaria. Sin embargo, el acceso a esta fuente energética es precario ya que en general las conexiones son clandestinas (en algunos casos no poseen medidores y en

\footnotetext{
2 Camuzzi Gas Pampeana es la empresa encargada del suministro de gas natural por red pública en la ciudad de Bahía Blanca.

${ }^{3}$ El Municipio de Bahía Blanca entrega garrafas a los hogares con mayores necesidades bajo el Plan "Garrafas de Emergencia", como también se otorgan descuentos ligados a la tenencia de otros planes sociales en entidades adheridas.

"Visión de Futuro" Año 18, Volumen No 25 No 1, Edición Especial-III Congreso Regional de Economía del Norte Grande-Pág 101-123 URL de la Revista: http://visiondefuturo.fce.unam.edu.ar/index.php/visiondefuturo/index

URL del Documento: https://visiondefuturo.fce.unam.edu.ar/index.php/visiondefuturo/issue/view/20

ISSN 1668 - 8708 - Versión en Línea

E-mail: revistacientifica@fce.unam.edu.ar
} 
otros los comparten entre varias familias). Este hecho genera problemas de sobrecargas a la red y cortes de suministro.

En síntesis, se observa que los hogares de 9 de Noviembre experimentan un conjunto de privaciones simultáneas que distan ampliamente de la realidad del aglomerado Bahía Blanca- Cerri. Esta situación no solo incluye a un menor ingreso por adulto equivalente (incidencia de la pobreza por ingresos) sino también a privaciones en el acceso a servicios básicos, calidad de la vivienda, sanidad y educación. En lo respectivo a privaciones energéticas, el barrio en su totalidad no cuenta con acceso a gas de red, muchas familias utilizan combustibles sólidos y elementos contaminantes para satisfacer sus servicios energéticos, la electricidad es la principal fuente utilizada para la calefacción y cocción, pero un número no despreciable de familias se encuentran ilegalmente conectadas al servicio. Por ello, es evidente que las personas y hogares de 9 de Noviembre se encuentran rezagados, en relación a sus pares del resto de la ciudad, en términos de desarrollo humano y bienestar.

\section{El proyecto según su plan original: etapas, planificación y diseño}

Como su nombre lo indica "Energías renovables como herramienta de reducción de la pobreza energética. Una prueba piloto en barrios vulnerables de Bahía Blanca" intenta evaluar mediante una prueba piloto, los aportes de nuevos sistemas de producción, control y gestión para la generación de una o más fuentes basadas en energías renovables y/o alternativas, para la solución de problemáticas relativas a la inaccesibilidad al sistema de energía distribuida; escasez de recursos/ artefactos para calefacción (en este caso para agua sanitaria caliente) en asentamientos irregulares y barrios en situación de vulnerabilidad. En otras palabras, luego de la elaboración e instalación de los artefactos construidos en conjunto con los propios beneficiarios, se realizará una evaluación de impacto sobre el nivel de bienestar en dichas familias, incorporando los impactos sobre privaciones energéticas, cambios en hábitos de consumo, gastos, utilización del tiempo, higiene familiar y salud.

El grupo de trabajo está compuesto por tres entidades. Así, participan miembros del Instituto de Investigaciones Económicas y Sociales del Sur (IIESS, UNS/CONICET), la Asociación Vicentina de Caridad (AVC) -entidad benéfica sin fines de lucro- y la Universidad Tecnológica Nacional -Facultad Regional Bahía Blanca. Los representantes de la AVC facilitan el contacto con los habitantes del barrio, brindando su conocimiento del terreno y coordinando los eventos relacionados a la metodología de aplicación.

La intervención se realizará en el barrio 9 de Noviembre y su elección responde a dos motivos.

\footnotetext{
"Visión de Futuro" Año 18, Volumen No 25 No 1, Edición Especial-III Congreso Regional de Economía del Norte Grande-Pág 101-123 URL de la Revista: http://visiondefuturo.fce.unam.edu.ar/index.php/visiondefuturo/index

URL del Documento: https://visiondefuturo.fce.unam.edu.ar/index.php/visiondefuturo/issue/view/20

ISSN 1668 - 8708 - Versión en Línea

E-mail: $\underline{\text { revistacientifica@fce.unam.edu.ar }}$
} 
En primer lugar, los miembros han trabajado en el barrio en proyectos previos, estableciendo relaciones con la comunidad y un relevamiento exhaustivo respecto de las condiciones socioeconómicas de la población, detalladas en el apartado precedente. A su vez, las características socio-económicas del barrio permiten caracterizarlo como vulnerable y conocer, además, que una proporción no despreciable de su población presenta privaciones energéticas, lo cual califica al sector como factible para aplicar una intervención como la planeada.

Para alcanzar los objetivos antes definidos, el proyecto propone un plan de acción en cuatro etapas. Primero, realizar un diagnóstico de las privaciones energéticas y conocer la valoración de los hogares sobre los diferentes servicios energéticos. Esto incluye la implementación de grupos focales. Segundo, se procede a instalar los colectores solares (al menos 10) en viviendas del barrio. Esta etapa contempla la realización de talleres para facilitar la construcción, instalación y mantenimiento del artefacto -tareas que serán realizadas en conjunto con los hogares beneficiarios-.

En tercer lugar, se contempla realizar un seguimiento y monitoreo del artefacto y los hogares. En este sentido se realizará el monitoreo técnico en el que se evaluará cómo funcionan los colectores, su durabilidad y mantenimiento. En cuarto lugar, se propone evaluar el impacto de esta política a partir de comparar los efectos entre el grupo que recibe el tratamiento y el grupo de control. Se propone la implementación de un ensayo aleatorio controlado. La evaluación contempla a indicadores relativos a las dinámicas de organización familiar, reducción en el consumo de otras fuentes energéticas e implicancias en términos de uso del tiempo y reducción en el gasto de los hogares.

Se esperan mejoras en la calidad de vida de los hogares receptores en términos de higiene, reducción de tiempo destinado a calentar agua, descenso del nivel de contaminación intrahogar -debido al reemplazo de acciones contaminantes para calentar agua-, mejoras en la salud de sus miembros y reducción en el gasto en energía.

La implementación del proyecto analizado equivale a la aplicación de una prueba piloto. En este sentido, la realización de la misma se refiere a la implementación del protocolo completo propuesto para el desarrollo de la actividad, pero en una escala menor. Esto permite validar el sistema de implementación y realizar los ajustes necesarios (Secretaría de Energía, 2019). Su implementación también permite obtener información sobre la experiencia de las propias familias interactuando con el prototipo (Judson et al., 2019) así como una valoración integral de la tecnología de interés -pudiendo identificar y cuantificar los beneficios y los costos, tanto generados como evitados, que obtienen los usuarios por el

\footnotetext{
"Visión de Futuro" Año 18, Volumen No 25 N 1, Edición Especial-III Congreso Regional de Economía del Norte Grande-Pág 101-123 URL de la Revista: http://visiondefuturo.fce.unam.edu.ar/index.php/visiondefuturo/index

URL del Documento: https://visiondefuturo.fce.unam.edu.ar/index.php/visiondefuturo/issue/view/20

ISSN 1668 - 8708 - Versión en Línea

E-mail: revistacientifica@fce.unam.edu.ar
} 
uso del artefacto-.

La metodología de evaluación de impacto de este proyecto consiste en un ensayo controlado aleatorio (RCT en inglés). Este método experimental es el estándar de referencia para la realización de inferencia causal entre un tratamiento y resultados de interés. Su implementación, sin embargo, representa una reducida proporción de los trabajos que analizan el impacto de programas. La principal limitación radica en el elevado costo que supone la implementación de este tipo de intervenciones. Por ello, este trabajo contribuye al análisis de la pobreza energética aportando evidencia experimental innovadora para el caso de Argentina.

En este contexto, la intervención definida por este proyecto es implementada según se detalla a continuación. Dado el universo de hogares localizados en el barrio, en la primera etapa se procede a realizar un relevamiento de los hogares -mediante entrevistas al jefe de hogar-. Esto permite conocer las condiciones pre-tratamiento e identificar a la población objetivo. Serán parte del ensayo aquellos hogares que no cuenten con ningún tipo de dispositivo para calentar agua dentro del hogar (calefones de cualquier tipo, termotanques o ducha eléctrica).

En la siguiente etapa, el tratamiento (instalación de calefones solares) es asignado al grupo de referencia. El grupo control no recibe ninguna intervención en esta etapa. La selección de ambos grupos, tratamiento y control, es realizada aleatoriamente dentro de la población objetivo según la terminación del documento de identidad del jefe de hogar.

El inicio del tratamiento estaba previsto para mayo de 2020. Transcurridos 90 días desde el inicio del tratamiento, se realiza el segundo relevamiento de hogares. Aquí se incluyen, únicamente, los hogares que participan del ensayo -tanto del grupo control como del tratamiento-. Con esta información es posible construir un panel de hogares y estimar el impacto del tratamiento a partir de un análisis re regresión estándar (Twisk et al., 2018).

La implementación de ensayos controlados aleatorios en Economía, y en general en Ciencias Sociales, supone desafíos adicionales -en relación a otras disciplinas-. Además de las frecuentes preocupaciones acerca de sus implicancias éticas y sobre el bienestar de los hogares participantes, en el actual contexto de pandemia surgen nuevas problemáticas. Primero, debido a las medidas de distanciamiento vigentes -y sus implicancias en términos de movilidad y contacto- no es factible la realización de encuestas de hogar mediante encuestadores in situ. Segundo, la realización de talleres con los participantes del proyecto e instalación de colectores también se ve limitada. Tercero, las profundas alteraciones socioeconómicas que surgen a raíz de este contexto pueden afectar la comparabilidad de ambos

\footnotetext{
"Visión de Futuro" Año 18, Volumen N$^{\circ} 25$ N 1, Edición Especial-III Congreso Regional de Economía del Norte Grande-Pág 101-123 URL de la Revista: http://visiondefuturo.fce.unam.edu.ar/index.php/visiondefuturo/index

URL del Documento: https://visiondefuturo.fce.unam.edu.ar/index.php/visiondefuturo/issue/view/20

ISSN 1668 - 8708 - Versión en Línea

E-mail: revistacientifica@fce.unam.edu.ar
} 
relevamientos de hogares que se realizan a fin de evaluar el impacto del programa.

A los efectos de minimizar las distorsiones generadas por las anteriores limitaciones, se procede de la siguiente forma. En primer lugar, el primero de los relevamientos de hogares se realiza entre aquellas personas que concurren a las instalaciones de AVC y la Sociedad de Fomento del barrio 4 . Esto permite recabar información pre-tratamiento, pero a riesgo de una pérdida no aleatoria de observaciones (personas de hogares que no concurren a las instalaciones de AVC porque no requieren ninguno de los servicios allí brindados).

En segundo lugar, la realización de talleres así como la instalación de los colectores se hará en forma secuencial de a pares de hogares. Es decir, en cada etapa de instalación recibirán el artefacto, no más, de dos hogares. Esto permite maximizar el tiempo promedio de tratamiento, aunque afecta la comparabilidad entre hogares beneficiarios (no todos reciben el tratamiento al mismo tiempo).

En tercer lugar, dada la excepcionalidad de la actual coyuntura es posible que algunos de los indicadores incluidos (prácticas de higiene, desempleo, asistencia a la escuela, etc.) presenten amplios cambios entre el primer y el segundo relevamiento de hogar y que esto pueda afectar la evaluación de impacto ${ }^{5}$. Para ello, se consideran, adicionalmente, otros indicadores que se conciben como más estables. Esto incluye a la incidencia de enfermedades, uso del tiempo y estatus de salud auto-percibido.

\section{Repensando el proyecto frente al contexto de aislamiento social por COVID- 19}

La Organización Mundial de la Salud (OMS) declaró el 11 de marzo de 2020 el estado de pandemia debido al brote de COVID-19. Luego, el gobierno argentino, con un bajo número de infectados, decretó, desde el 20 de marzo, el aislamiento preventivo y obligatorio en todo el territorio. Esta medida fue extendida posteriormente (Decreto 297/2020). La Provincia de Buenos Aires definió medidas estrictas para avanzar en el relajamiento de estas medidas (Decreto 498/2020). Así, para acceder a la denominada etapa 5 un municipio debe acreditar que, en los 21 días previos, no presenta casos confirmados de COVID-19.

Al igual que el resto de la nación, la ciudad de Bahía Blanca entró en cuarentena en la misma fecha, con el primer caso positivo de COVID-19 confirmado dos días antes. Aunque el nivel de propagación del virus fue leve (alrededor de 30 casos confirmados), la fase más rígida del aislamiento social se extendió hasta mediados del mes de abril. En el transcurso

\footnotetext{
${ }^{4}$ A este predio las familias pueden concurrir para recibir atención básica de salud, bolsones de alimentos o vestimenta (en días y horarios definidos previamente).

${ }^{5}$ Se estima que el segundo relevamiento sea realizado en el contexto de la denominada "nueva normalidad" (libre circulación, clases presenciales, etc.).

"Visión de Futuro" Año 18, Volumen $N^{0} 25$ N$^{\circ}$ 1, Edición Especial-III Congreso Regional de Economía del Norte Grande-Pág 101-123 URL de la Revista: http://visiondefuturo.fce.unam.edu.ar/index.php/visiondefuturo/index

URL del Documento: https://visiondefuturo.fce.unam.edu.ar/index.php/visiondefuturo/issue/view/20

ISSN 1668 - 8708 - Versión en Línea

E-mail: revistacientifica@fce.unam.edu.ar
} 
de esas semanas y debido a gestiones municipales, el gobierno provincial autorizó a habilitar algunas actividades básicas (pago de impuestos, retiro de productos elaborados en casas de comidas, atención médica y odontológica programada, entre otras).

El primer deceso a causa del virus en la ciudad se produjo el 5 de mayo cuando un hombre de 65 años falleció en un nosocomio local, aunque había sido contagiado fuera del conglomerado. El mismo poseía con afecciones previas y condiciones de salud desfavorables.

En consonancia con las decisiones a nivel nacional, las cuales reglamentan diferentes regímenes de aislamiento según las condiciones de propagación, las actividades permitidas, tanto sociales como comerciales, habilitadas continuaron sumándose debido al control de los focos de contagio. Así, a mediados del mes de mayo se habilitó a los bahienses a realizar salidas recreativas los fines de semana (con medidas de protección y de distancia). Semanas después, fue permitida la actividad física deportiva en espacios abiertos, con limitaciones horarios, distancia y tiempo de actividad, quedando excluidas las actividades grupales.

Luego de presiones ante la falta de actividad comercial y el inicio de controles sanitarios en los accesos terrestres a la ciudad, el 11 de junio se estableció en la ciudad la "fase 4", con la cual fue habilitada la venta de indumentaria y calzado. Otro factor clave para la liberación de la circulación es el número de días de duplicación de casos, el cual se encontraba en una cifra superior a los 35 días, como también fue determinante la reducción de los focos de contagio con seguimiento de pacientes y sospechosos, testeos y demás controles.

Es dable destacar que la circulación social es ampliamente superior a la del aislamiento más rígido, los controles de circulación por parte de las fuerzas de seguridad son menos estricto dentro de la zona urbana y la gran mayoría de las entidades públicas operan con atención al público. Aun así, en los primeros días del mes de julio, no se encuentran permitidas las reuniones ni fueron habilitados los establecimientos donde se generan aglomeraciones de personas (bares, restaurantes, etc.), como tampoco el desplazamiento para actividades de esparcimiento en grupos. Al 6 de julio, Bahía Blanca acumula 124 casos confirmados. De éstos, 40 son casos activos. El tiempo de duplicación de contagios es de 8 días.

Debido a dichas restricciones, las actividades relativas a trabajo de campo necesarias en el marco de este proyecto (censo de condiciones socioeconómicas de la población, talleres de capacitación en la construcción, mantenimiento y limpieza de los colectores solares y grupos focales) no están autorizadas. Por tal motivo, algunas estrategias han sido modificadas y otras trasladadas en el espacio temporal del proyecto.

\footnotetext{
"Visión de Futuro" Año 18, Volumen No 25 Nº 1, Edición Especial-III Congreso Regional de Economía del Norte Grande-Pág 101-123 URL de la Revista: http://visiondefuturo.fce.unam.edu.ar/index.php/visiondefuturo/index

URL del Documento: https://visiondefuturo.fce.unam.edu.ar/index.php/visiondefuturo/issue/view/20

ISSN 1668 - 8708 - Versión en Línea

E-mail: revistacientifica@fce.unam.edu.ar
} 
En este sentido, la propuesta metodológica contemplaba, una vez realizada la caracterización de los hogares, organizar talleres con los vecinos del barrio. El objetivo de estos espacios es instruir a los participantes en el armado y funcionamiento de colectores solares. Con posterioridad a los talleres, se seleccionarían 10 familias (de las asistentes a los talleres) de manera aleatoria y se colocarían los colectores solares en sus hogares. Bajo el mismo procedimiento se conformaría el grupo control con otras 10 familias de similares condiciones socioeconómicas.

Por la situación de aislamiento social preventivo y obligatorio, no fue posible avanzar en la realización de los talleres y por tanto la estrategia de implementación debió ser modificada.

En primer lugar, en lugar de comenzar en la construcción y colocación de 10 colectores, se decidió hacer una primera etapa de únicamente 2 colectores solares. En segundo lugar, se optó por seleccionar 2 familias dentro de un grupo de 8 familias, que han concurrido a talleres de capacitación brindados por la UTN en el centro AVC con anterioridad. Por último, se elegirán 2 familias del resto de la población del barrio que tengan características similares a las familias beneficiarias, de manera tal que sean el grupo de control.

Con respecto a las actividades de seguimiento y monitoreo, las mismas se desarrollarán de igual manera de la que fue planeada inicialmente. En otras palabras, el seguimiento de las familias que conformen los grupos tratamiento y control se efectuará a través de entrevistas continuas (telefónicas o presenciales) para evaluar el impacto de la tecnología en el bienestar de las familias.

Tal como fue comentado anteriormente, en el marco del proyecto, una de las actividades estipuladas es la caracterización socioeconómica del barrio. Si bien se cuenta con el relevamiento realizado en el año 2016 en el marco del PDTS 392 (London et al., 2019), el nuevo relevamiento propone actualizar dicha información y profundizar las estadísticas respectivas a percepción, bienestar y privaciones energéticas.

Una primera etapa de este relevamiento comenzó con la habilitación de la fase cuatro de las medidas de distanciamiento social, durante el mes de junio. Este nuevo panorama implicó un cambio en la estrategia de recolección de datos. Así, las encuestas no se realizan en cada hogar, sino que se aplica el cuestionario a las familias que asisten al Centro de la Asociación Vicentina de Caridad por diversos motivos: búsqueda de bolsones de comida, vacunación, asistencia pediátrica, búsqueda de ropa, entre otros. Según los referentes de ambas instituciones, las familias que asisten son más de 150, por lo que la cobertura sería amplia (de un total de 300). Sin embargo, con el objetivo de realizar un censo en el barrio, se completará el relevamiento cuando las actividades de campo estén autorizadas. Por otro lado, a fin de

\footnotetext{
"Visión de Futuro" Año 18, Volumen No 25 N 1, Edición Especial-III Congreso Regional de Economía del Norte Grande-Pág 101-123 URL de la Revista: http://visiondefuturo.fce.unam.edu.ar/index.php/visiondefuturo/index

URL del Documento: https://visiondefuturo.fce.unam.edu.ar/index.php/visiondefuturo/issue/view/20

ISSN 1668 - 8708 - Versión en Línea

E-mail: revistacientifica@fce.unam.edu.ar
} 
poder relevar en forma expeditiva se realizó un cuestionario de preguntas con opción múltiple y concentrados en los datos del jefe del hogar (sin aplicar las preguntas a todos los miembros, como fue planeado originalmente). Una vez conformados los grupos control y tratamiento se profundizará en la evaluación de las condiciones socioeconómicas de los hogares seleccionados para completar la información.

En esta primera etapa, llevada a cabo durante tres jornadas, se han relevado a 80 hogares del barrio 9 de Noviembre. En este primer conjunto de encuestas se encuentra una fuerte preponderancia en el uso de garrafas para la cocción y obtención de agua caliente sanitaria. Un caso algo distinto resulta la estrategia de los vecinos en la calefacción del hogar, donde se visualiza el uso de artefactos eléctricos y la combustión de leña y residuos como opciones principales.

Al consultar a los respondientes respecto a su nivel de satisfacción en relación a la cantidad de garrafas a las que accede, el 90\% manifestó poseer necesidades energéticas insatisfechas. Con menor frecuencia, el $76 \%$ de los encuestados consideró que la forma en la que acceden al agua caliente sanitaria condiciona sus hábitos de higiene personal, la limpieza del hogar y el lavado de ropa, entre otros.

Por otra parte, en el cuestionario se indaga acerca de si las personas estarían dispuestas a participar en la construcción del colector solar para sus hogares. La respuesta fue positiva en la totalidad de los casos analizados, sin embargo, una proporción no despreciable de los encuestados aclaró que no estaría en condiciones de afrontar ningún costo del artefacto.

Así, es visible que la pandemia ha modificado el cronograma y los planes iniciales del proyecto, dificultando la obtención de resultados y avances previstos. Sin embargo, se ha avanzado tanto en la etapa de diagnóstico como en la transferencia tecnológica, aunque en una menor escala. La ejecución del proyecto, dado el nuevo contexto, se hará en etapas: se instalarán de a dos colectores solares por mes, hasta que las condiciones sanitarias permitan hacer los talleres con mayor cantidad de personas. Los talleres también se realizarán de forma secuencial, con las familias que recibirán el tratamiento. Adicionalmente, en función de la selección de esas familias (en la encuesta se consultó por la intención de participar en la coconstrucción) se construirá el grupo control a partir de los datos obtenidos en las encuestas (las familias deben tener las mismas características para ser comparables).

El seguimiento también se ajustará a este esquema de etapas, por lo que el monitoreo de las familias de ambos grupos (control y tratamiento) se irá haciendo de forma escalonada en función del momento de la instalación. Se prevé un monitoreo continuo mediante entrevistas semiestructuradas con distintos miembros del hogar, evaluando diversas dimensiones del

\footnotetext{
"Visión de Futuro" Año 18, Volumen Nº 25 N 1, Edición Especial-III Congreso Regional de Economía del Norte Grande-Pág 101-123 URL de la Revista: http://visiondefuturo.fce.unam.edu.ar/index.php/visiondefuturo/index

URL del Documento: https://visiondefuturo.fce.unam.edu.ar/index.php/visiondefuturo/issue/view/20

ISSN 1668 - 8708 - Versión en Línea

E-mail: revistacientifica@fce.unam.edu.ar
} 
bienestar. La modalidad presencial o telefónica de este seguimiento también está sujeto a la evolución de las fases de la pandemia.

Finalmente, la evaluación de impacto programada a través de experimentos controlados y grupos focales será postergado para el momento que la situación sanitaria lo permita. Es dable destacar que estas herramientas son centrales para analizar el impacto de la transferencia tecnológica realizada como la valoración de los agentes respecto del servicio energético de agua caliente sanitaria. Aspectos centrales para considerar la ampliación de escala de la política. A su vez, la utilización de grupos focalizados se justifica dado que permiten conocer las ideas colectivas de un programa social o comunitario, ya sea para su formulación o evaluación y constituye una síntesis de opiniones y orientaciones que permiten conocer la experiencia y vivencia de los agentes colectivos (Sautú, 2009).

\section{CONCLUSIÓN}

El presente trabajo detalló la planificación definida para la realización de una prueba piloto de co-construcción e instalación de colectores solares en el barrio 9 de Noviembre de Bahía Blanca, con el fin de proveer agua caliente sanitaria a los hogares que presentan privaciones de acceso. De esta propuesta forman parte diversas instituciones educativas, técnicas, de investigación y sociales. La misma incluye talleres de instrucción técnica para la auto- construcción de los artefactos por parte de los beneficiarios, como también el seguimiento técnico y de evolución del bienestar y comportamiento de los hogares tratados. De esta manera, se espera que genere efectos positivos en los hogares beneficiarios, como también información precisa sobre la eficiencia de los aparatos y la factibilidad de una posible extensión de la intervención en espacios más amplios.

La irrupción del brote mundial de COVID-19 y la posterior cuarentena decretada en Argentina a mediados del mes de marzo, detuvo los avances del proyecto y obligó a cambiar la planificación de intervención, retrasando/reprogramando tareas y modificando la metodología de aplicación.

Así, la primera etapa de avance del proyecto, que consta de las encuestas para caracterización de la población del barrio fueron realizadas en ámbitos diferentes a los planeados, con algunos limitantes de número y sesgo. A partir de las mismas se logró obtener información fehaciente acerca de la situación de educación, ingresos, salud, vivienda, fuentes energéticas utilizadas y obtención de agua caliente sanitaria, además relevar la aceptación generalizada de la aplicación del proyecto, de los hogares del barrio. De la misma manera, para respetar el distanciamiento obligatorio, los talleres de

\footnotetext{
“Visión de Futuro" Año 18, Volumen $N^{\circ} 25$ No 1, Edición Especial-III Congreso Regional de Economía del Norte Grande-Pág 101-123 URL de la Revista: http://visiondefuturo.fce.unam.edu.ar/index.php/visiondefuturo/index

URL del Documento: https://visiondefuturo.fce.unam.edu.ar/index.php/visiondefuturo/issue/view/20

ISSN 1668 - 8708 - Versión en Línea

E-mail: revistacientifica@fce.unam.edu.ar
} 
autoconstrucción de los colectores serán más reducidos, por lo que el número de artefactos a instalar será menor en un principio. Estas cuestiones cambian la lógica del proyecto hacia un proceso en etapas, distinta a la implementación total que se planeaba.

Uno de los aportes principales del presente desarrollo es la contribución a favor de la factibilidad y ventajas de la aplicación de experimentos en la investigación en las ciencias sociales. Sin embargo, las características propias de la realidad en contextos sociales la tornan incierta e incontrolable, reduciendo las probabilidades de implementación exacta del diseño previsto.

Los sucesos imprevistos y las dificultades que los mismos acarrean -como fueron la pandemia y el aislamiento preventivo- pueden constituir una fortaleza adicional en los experimentos en ámbitos sociales, dado que éstos no simplifican la realidad, sino que adaptan su complejidad y producen resultados con alto un nivel de significancia (Ostrom, 2000).

Por último, es dable destacar la capacidad de adaptación requerida para la adecuación de actividades y metodologías de intervención de los encargados de la investigación científica en ciencias sociales. En este sentido, los acontecimientos imponderables ya mencionados obligaron a replantear la planificación del proyecto a fines de mantener la calidad de la intervención y la representatividad de los resultados a obtener, atendiendo las restricciones impuestas. Considerando lo anterior, el vínculo con los vecinos y el rol activo de AVC jugaron un rol fundamental para avanzar y adaptar los planes originales.

\section{REFERENCIAS}

Alkire, Sabine, \& Santos, Maria Emma (2010). Acute multidimensional poverty: A New index for developing countries. Documento de trabajo 38, OPHI.

Arévalo, Carla, \& Paz, Jorge (2015). Pobreza en Argentina. Privaciones múltiples y asimetrías regionales. Documento de Trabajo 15, Instituto de Estudios Laborales y del Desarrollo Económico (UNSa).

Becher, Pablo Ariel \& Martín, Juan Manuel (2016). Conflictividad social, cooperativismo y precarización laboral: El caso de la Cooperativa Cartoneros del Sur en Bahía Blanca (2007- 2014). Trabajo y sociedad: Indagaciones sobre el empleo, la cultura y las prácticas políticas en sociedades segmentadas, (27): 517-537.

Brown, Caitlin, Ravallion, Martin, \& van de Walle, Dominique (2020). Can the world's poor protect themselves from the new coronavirus?. Working paper 27200, NBER.

Calle Espinoza, Cristina; London, Silvia \& Pérez, Stella Maris (2016). Migración, pobreza y segregación urbana en una ciudad intermedia como Bahía Blanca. Conflicto Social,

\footnotetext{
"Visión de Futuro" Año 18, Volumen N$^{\circ} 25$ N 1, Edición Especial-III Congreso Regional de Economía del Norte Grande-Pág 101-123 URL de la Revista: http://visiondefuturo.fce.unam.edu.ar/index.php/visiondefuturo/index

URL del Documento: https://visiondefuturo.fce.unam.edu.ar/index.php/visiondefuturo/issue/view/20

ISSN 1668 - 8708 - Versión en Línea

E-mail: revistacientifica@fce.unam.edu.ar
} 
9(16): 34- 59.

Diaz, Lucía (2017). Políticas de integración urbana. Un análisis del caso de Bahía Blanca.

Bahía Blanca: Universidad Nacional del Sur. Tesis de grado.

Formichella, María Marta, Krüger, Natalia \& Reyes Pontet, Mauro David (2017). Condiciones socioeducativas heterogéneas en barrios periféricos de Bahía Blanca. Actas del VI Congreso Nacional e Internacional de Estudios Comparados en Educación.

Gobierno Municipal de Bahía Blanca (2020). La ciudad de Bahía Blanca. Bahía web. Disponible en: https://www.bahia.gob.ar/ciudad/. Consultado el 20 de abril de 2020.

lbáñez Martín, María María; Formichella, María Marta \& Costabel, Lucas Ezequiel (2019).

Exclusión social: explorando la dimensión educativa en Argentina. Problemas del

Desarrollo. Revista Latinoamericana de Economía, 51(200):103-129.

INDEC (2019). Informe de Incidencia de la pobreza e indigencia en 31 aglomerados urbanos. Informes Técnicos, 3(182). INDEC.

Judson, Ellis, Zirakbash, Farnaz, Nygaard, Andi, \& Spinney, Angela (2019). Renewable Energy Retrofitting and Energy Poverty in Low-income Households: final report. Australian Policy Online [en línea]. Disponible en: https://apo.org.au/node/256996 [Consultado el 7 de mayo de 2020].

Kruger, Natalia, \& Formichella, María Marta (2018). Oportunidades educativas reducidas para niños y jóvenes en barrios informales de Bahía Blanca, Argentina. Ensayos de Política Económica, 2(6):71-92.

London, Silvia, Alderete, María Verónica, Formichella, María Marta, Girón, Pablo, Ibañez Martín, María María, Krüger, Natalia, Pérez, Stella Maris, Segurado, Valentina, Verna, Roberto, Viego, Valentina \& Walker, Verónica (2019). Informe final del proyecto Diseño de estrategias para mejorar las oportunidades educativas de la población vulnerable de Bahía Blanca a través de la ONG Red de Voluntarios. Documentos de trabajo. Instituto de InvestigacionesEconómicas y Sociales del Sur, UNS-CONICET. Disponible en: https://iiess.conicet.gov.ar/index.php/investigacion/publicaciones-grales/documentosde- trabajo

Malisani, Débora (2017). La política de integración urbana en Bahía Blanca a la luz del presupuesto municipal. Bahía Blanca: Universidad Nacional del Sur. Tesis de grado.

Muñoz Cantero, Jesús Miguel \& Rebollo Quintela, Nuria (2016). Evaluación del impacto de políticas orientadas a la inserción sociolaboral mediante matching. Revista de Investigación Educativa, 34(1):87-102. DOI: http://dx.doi.org/10.6018/rie.34.1.206871

\footnotetext{
"Visión de Futuro" Año 18, Volumen Nº 25 N 1, Edición Especial-III Congreso Regional de Economía del Norte Grande-Pág 101-123 URL de la Revista: http://visiondefuturo.fce.unam.edu.ar/index.php/visiondefuturo/index

URL del Documento: https://visiondefuturo.fce.unam.edu.ar/index.php/visiondefuturo/issue/view/20

ISSN 1668 - 8708 - Versión en Línea

E-mail: revistacientifica@fce.unam.edu.ar
} 
Navarro, Ana Inés \& Vanesa Valeri D'Elia (2011). The Impact of the Universal Child Allowance on Argentina's Children Schooling Gap. Disponible en: SSRN: https://ssrn.com/abstract=1924946 or http://dx.doi.org/10.2139/ssrn.1924946

Organización Mundial de la Salud (2020). Coronavirus disease advice for the public. Disponible en: https://www.who.int/emergencies/diseases/novel-coronavirus2019/advice-for- public

Ostrom, Eleonor (2000). Diseños complejos para manejos complejos. Gaceta Ecológica, 54: 43-58.

Pérez, Stella Maris (2015). Desarrollo urbano y desigualdad en Bahía Blanca. Estudios Económicos, 24(48):57-82.

Prieto, María Belén (2008). Fragmentación socio-territorial y calidad de vida urbana en la ciudad de Bahía Blanca. Geografiando: Revista de Estudios Geográficos, 4:1-22.

Rajeev, Dehejia \& Wahba, Sadek (1999). Casual Effects in Non-Experimental Studies: ReEvaluating the Evaluation of Training Programs. Journal of the American Statistical Association, 94 (448):1053.

Ramborger, María Alejandra, Campo, Alicia \& Lorda, María Amalia (2018). Confort climático del sector norte y sur de la ciudad de Bahía Blanca. Geograficando: Revista de Estudios Geográficos, 14(1):1-14.

Ravallion, Martin (2020). Pandemic policies in poor places. Nota del Center for Global Development. Disponible en: https://www.cgdev.org/publication/pandemic-policiespoor- places.

RENABAP (2018). Mapa de Barrios Populares en Argentina. Disponible en: https://www.argentina.gob.ar/renabap. Consultado el 16 de abril de 2020.

Reyes Pontet, Mauro, London, Silvia (2019). Análisis de la situación de los barrios vulnerables de bahía blanca: las desventajas medioambientales como contribución a las trampas de pobreza. Actas del Seminario Internacional de Energía, innovación y ambiente para una transición energética: retos y perspectivas. Bahía Blanca, 27 y 28 de junio de 2019.

Santos, Maria Emma (2020). Pobreza Multidimensional en Argentina y Bahía Blanca en tiempos del COVID-19. Documento de Trabajo, 14. Instituto de Investigaciones Económicas y Sociales del Sur. Disponible en: https://iiess.conicet.gov.ar/index.php/investigacion/publicaciones-grales/documentosde- trabajo

Santos, Maria Emma, \& Villatoro, Pablo (2018). A multidimensional poverty index for Latin

\footnotetext{
"Visión de Futuro" Año 18, Volumen No 25 N 1, Edición Especial-III Congreso Regional de Economía del Norte Grande-Pág 101-123 URL de la Revista: http://visiondefuturo.fce.unam.edu.ar/index.php/visiondefuturo/index

URL del Documento: https://visiondefuturo.fce.unam.edu.ar/index.php/visiondefuturo/issue/view/20

ISSN 1668 - 8708 - Versión en Línea

E-mail: $\underline{\text { revistacientifica@fce.unam.edu.ar }}$
} 
America. The Review of Income and Wealth, 64(1):52-82.

Sautú, Ruth. (2009). El marco teórico en la investigación cualitativa. Controversias y concurrencias latinoamericanas, 1(1):155-177.

Secretaría de Energía (2019). Programa Nacional de Etiquetado de Viviendas: Informe Técnico [pdf]. Disponible en https://www.argentina.gob.ar/sites/default/files/201911_ev2019_informe_tecnico.pdf. [Consultado el 20 de abril de 2020].

TECHO (2016). Relevamiento de Asentamientos Informales. TECHO. Disponible

https://www.techo.org/argentina/wp-content/uploads/sites/3/2019/04/Informe-

Relevamiento-de-Asentamientos-Informales-2016-TECHO-Argentina.pdf. Consultado el 20 de abril de 2020.

Tornarolli, Leopoldo (2018). Series comparables de indigencia y pobreza: una propuesta metodológica. Documento de trabajo 226, CEDLAS.

Twisk, Jos, Bosman, Lisa, Hoekstra, Trynke, Rijnhart, Judith, Welten, Marieke, \& Heymans, Martijn. (2018) Different ways to estimate treatment effects in randomised controlled trials. Contemporary Clinical Trials Communications, 10:80-85.

Urriza, Guillermina (2018). Expansión urbana en ciudades intermedias de crecimiento demográfico bajo. el caso de Bahía Blanca, Argentina. Revista Universitaria de Geografía, 23 (2):97-123.

\section{RESUMEN BIBLIOGRÁFICO}

\section{Fernando Antonio González}

Magister en Economía por la UNS. Es Becario Doctoral en el Instituto de Investigaciones Económicas y Sociales del Sur, UNS-CONICET y Docente en el Departamento de Economía, UNS. Su principal área de interés es el estudio de los impactos, micro y macro económicos, de los desastres naturales.

\section{Mauro David Reyes Pontet}

Licenciado en Economía por la UNS desde 2017. Becario Doctoral del CONICET y Ayudante "B" con dedicación simple en la cátedra de Economía en el Departamento de Economía de la UNS. Trabaja en la temática: Pobreza y medioambiente en contextos urbanos bajo la dirección de Silvia London.

\section{María Florencia Zabaloy}

Es Doctora en Economía por la UNS. Actualmente se desempeña como docente del Departamento de Economía de la UNS y como becaria doctoral de CONICET. Se encuentra investigando políticas de eficiencia energética en el sector residencial argentino bajo la dirección de Marina Recalde y Carina Guzowski.

\section{María María Ibáñez Martín}

Es Doctora en Economía por la UNS, Becaria Posdoctoral del CONICET y docente en el

\footnotetext{
“Visión de Futuro" Año 18, Volumen $\mathbf{N}^{\circ} 25$ No 1, Edición Especial-III Congreso Regional de Economía del Norte Grande-Pág 101-123 URL de la Revista: http://visiondefuturo.fce.unam.edu.ar/index.php/visiondefuturo/index

URL del Documento: https://visiondefuturo.fce.unam.edu.ar/index.php/visiondefuturo/issue/view/20

ISSN 1668 - 8708 - Versión en Línea

E-mail: revistacientifica@fce.unam.edu.ar
} 
Departamento de Economía de la UNS. Trabaja en el área de Desarrollo Económico, con énfasis en el desarrollo de indicadores y medición de fenómenos sociales, en los cuales posee publicaciones en revistas especializadas y participaciones en congresos.

\section{Silvia London}

Doctora en Economía por la UNS. Investigadora Principal CONICET, Directora del IIESS (UNSCONICET). Profesora titular del Departamento de Economía de la UNS, donde obtuvo su doctorado en Economía (1999). Investiga sobre desarrollo económico, con énfasis en análisis institucional, trampas de pobreza y desarrollo sostenible, centrándose en mecanismos formales y empíricos que conducen a situaciones de estancamiento y pobreza.

\footnotetext{
“Visión de Futuro" Año 18, Volumen No 25 № 1, Edición Especial-III Congreso Regional de Economía del Norte Grande-Pág 101-123 URL de la Revista: http://visiondefuturo.fce.unam.edu.ar/index.php/visiondefuturo/index

URL del Documento: https://visiondefuturo.fce.unam.edu.ar/index.php/visiondefuturo/issue/view/20

ISSN 1668 - 8708 - Versión en Línea

E-mail: revistacientifica@fce.unam.edu.ar
} 